\title{
Vigilância em saúde e controle de doenças na Organização Pan-americana de saúde e a globalização
}

Na década de 80, a palavra globalização passou a adquirir um significado bem mais amplo do que o até então usado. De início, mais associada a aspectos econômicos, como liberalização do comércio, desregulação doméstica, privatização, investimentos estrangeiros e capitais voláteis. Resultando em desenvolvimento, instabilidade e desigualdade e exercendo influência complexa sobre a saúde. Está relacionada à preservação ambiental. Simples mudanças climáticas, como o aumento da temperatura, podem exercer efeitos desastrosos sobre os vetores das doenças (distribuição, reprodução, picadas), e sobre os patógenos (virulência, infecciosidade, alteração dos períodos de incubação das doenças). Especula-se sobre a volta da malária na Europa, aparecimento da febre amarela na Índia, epidemias de encefalites, etc. 0 nível e a temperatura do mar, influindo no zooplancton, reservatório de Vibrio cholera. Aumento da radiação ultravioleta beta, produz alteração do sistema imune e incremento dos casos de melanoma. Sem falar em outras consequiências extremas, enchentes, secas, efeito estufa, chuva ácida, etc.

A dominação humana do ecossistema terrestre, através da introdução de flora e fauna não nativas às novas áreas, está aumentando a homogeneidade biogeográfica global. Nas três últimas décadas, temos tido uma nova doença emergente ou reemergente por ano. Este aumento das doenças infecciosas da vida animal constitui uma ameaça à saúde humana.

Após cem anos, a luta contra as doenças endêmicas prossegue, evidentemente com reformulação

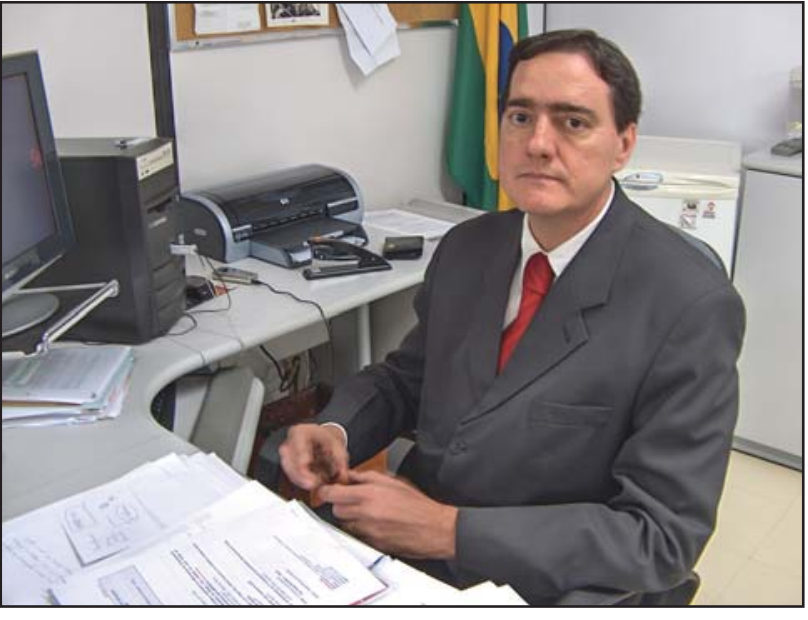

Dr.Jarbas Barbosa da Silva Júnior estrutura e do pessoal disponível em cada país para implantar as recomendações propostas e na obtenção do financiamento junto às autoridades doadoras de recursos.

Importante setor da Organização Pan-americana de Saúde - Vigilância em Saúde e Controle de doenças - é responsável pelo controle das doenças no Continente Americano. Não somente das doenças transmissíveis, com potencialidade de produzir pandemias, como a síndrome respiratória aguda e a gripe aviária, mas também outros problemas médicos como hipertensão arterial, tabagismo e obesidade, principalmente em jovens.

Evidentemente não é tarefa fácil escolher um nome capaz de coordenar esta área. A disputa foi demorada e dela fizeram parte 183 concorrentes, conforme noticiou o Jornal O Estado de São Paulo. Por fim, foi selecionado para o posto o sanitarista Jarbas Barbosa da Silva Júnior. O Doutor Jarbas graduou-se em Medicina (1981) pela Universidade Federal de Pernambuco e especializou-se em Saúde da metodologia de trabalho, com mais ênfase na abordagem multidisciplinar, nas relações parasita-hospedeiro, suscetibilidade e resistência às infecções, técnicas de biologia molecular, genética e imunológica, prioridade no controle e profilaxia, inclusão do assunto nos programas de saúde. Dentro das perspectivas de descentralização das ações, participação comunitária, atenção primária de saúde, programa de saúde da família, equilíbrio ecológico, imunizações e valorização das informações e dos conhecimentos. Partindo-se da premissa de vulnerabilidade, maior ou menor, de qualquer país estabeleceu-se uma rede global de alerta e de resposta a epidemias (OMS), para detecção sistemática, avaliação do surto, alerta precoce e resposta rápida.

Com a globalização tornou-se cada vez mais difícil circunscrever as epidemias somente estabelecendo barreiras sanitárias.

As autoridades de saúde estão muito ativas na adaptação da legislação sanitária internacional, no inventário da infraPública (1984) e em Epidemiologia (1989), pela Escola Nacional de Saúde Pública (FIOCRUZ). Fez Mestrado em Ciências Médicas (1995) e Doutorado em Saúde Coletiva (2004) pela Universidade Estadual de Campinas. É professor adjunto (Licenciado) da Universidade Federal de Pernambuco. Enquanto completava sua formação acadêmica Jarbas teve oportunidade de trabalhar em Unidades de Saúde. Assim, foi Secretário Municipal de Saúde de Olinda (1993-1994), Secretário Estadual de Saúde de Pernambuco (1995-1996), Diretor do Centro Nacional de Epidemiologia (CENEPI/FUNASA/Ministério da Saúde 1997-2003) Secretário de Vigilância em Saúde do Ministério daSaúde (2003-2006). Atualmente, éConsultor Legislativo Licenciado do Senado Federal e Secretário Executivo do Ministério da Saúde. Tem experiência na área de Saúde Coletiva, com ênfase em epidemiologia, principalmente da Saúde Publica, vigilância epidemiológica, prevenção e controle de doenças, política, planejamento e Gestão em Saúde. Como Consultor, Colaborador, Assessor, Conselheiro, ou Perito sempre participou de Comissões, Grupos, Conselhos que se reuniam para discutir os mais diversos assuntos de saúde, em diferentes níveis. No âmbito nacional, como autoridade governamental, municipal, estadual ou federal e em instituições de pesquisa (Instituto de Tecnologia Imunológica Bio-Manguinhos, Centro de Pesquisa Aggeu Magalhães, Fundação Oswaldo Cruz - FIOCRUZ, Instituto Butantã), ou em Sociedades científicas ou congressos (Sociedade Brasileira para o Progresso da Ciência, Sociedade Brasileira de Medicina Tropical, Congresso 
Brasileiro de Epidemiologia, Mostra Nacional de Experiências Bem Sucedidas em Epidemiologia, Fórum de Epidemiologia e Saúde Ambiental, Avanços e Perspectivas do Programa Nacional de Imunização e Vacinação, Congresso Brasileiro de Saúde Coletiva, etc), participando ativamente das discussões e na elaboração de documentos de trabalho sobre Metodologia para Avaliação do Sistema Nacional de Vigilância Epidemiológica, Epidemiologia no SUS, Desigualdade na Saúde, Controle da Doença de Chagas, Leishmanioses, Política Nacional de Imunização no Brasil, Descentralização de Ações, 0 Controle das Endemias e o Sistema de Vigilância Epidemiológica, Estratégia de Investigação em Serviços de Saúde, Doenças Emergentes no Brasil, Sarampo e a Estratégia para seu Controle, Avaliação do Plano Nacional de Controle do Hantavírus, SUS e o Processo de Municipalizações das Ações em Pernambuco, Repensando a Assistência Ambulatorial à Criança, Avaliação Prática na Implantação do SUS nos Estados e Municípios, Contribuição da Epidemiologia na Superação das Desigualdades em Saúde no SUS, Gestão de Saúde nos Municípios, Discussão da Saúde Coletiva no Brasil, AIDS, Atenção Primária de Saúde na Adolescência, DST, AIDS Realidade e Preconceito. A partir de 1987, vem participando ativamente da implantação de várias ações que têm modificado a filosofia de atuação do Ministério da Saúde, como o Sistema Único de Saúde, Programa da Saúde da Familia, Descentralização das atividades, Rede de Alerta Precoce e Resposta às Epidemias.

No âmbito internacional, tem se esforçado para estreitar a cooperação comoutros países e entidades estrangeiras. Membro doStrategic Advisory Group of Experts (SAGE) em vacinas e imunizações (2002-2005). Participou de várias reuniões com sanitaristas e autoridades sanitárias dos países da região amazônica, sobre saúde das populações indígenas, no Mercosul sob alerta e resposta a surtos de doenças transmissíveis, sessão do Conselho Diretor da OPS (2000), do Conselho Executivo da OMS (2002) da Assembléia da OMS (1999, 2000, 2001 e 2003), Congresso Internacional de Medicina Tropical e Malária (2000). Suas idéias sobre os vários temas acima mencionados, constam de relatórios, conferências e outros documentos, sendo que 16 trabalhos foram publicados em Revistas Indexadas e de circulação internacional. Muitas dessas contribuições são sobrepesquisa operacional. Participou de bancas examinadoras sendo oito teses de mestrado e uma de doutorado.

Entre prêmios e medalhas recebidos destacam-se do Instituto Butantã (2001), do Governo do Estado de São Paulo, da OPAS (2002) de reconhecimento, Comendador da Ordem do Mérito Médico (2002) da Presidência da Republica do Brasil e Ordem do Mérito Médico, do Governo do Estado de Minas Gerais.

\section{Aluízio Prata}

